\title{
Effect of hole diameter on ultimate bearing capacity of hollow-core slabs by finite element method
}

\author{
Muhammed MALEKNIA ${ }^{* 1}$, Ataollah Hajati ModARAEI ${ }^{2}$, Mostafa RADMEHR ${ }^{3}$ \\ ${ }^{1 .}$ MS of Structural Engineering, University of Guilan, mohamad_maleknia@yahoo.com \\ 2. Assistant Professor, Islamic Azad University of Bandar Anzali \& Guilan University, \\ dr.modaraei@gmail.com \\ 3. MS of Structural Engineering, Islamic Azad university South Tehran unit, \\ mostafa_radmehr@yahoo.com
}

\begin{abstract}
In recent years, extensive studies have been conducted on the load bearing and main members of reinforced concrete structures such as concrete beams, columns and slabs under shear, bending and even torsion to determine the ultimate bearing capacity of the members. Despite extensive research in these areas, little research activities have been done on a type of slab called hollow-core concrete slab. Also, the effect of hollow-core hole diameter on the volume of concrete placing, weight of the slab and consequently, of the entire structure, as well as the cost of construction and finally, the ultimate bearing capacity of hollow-core slabs is a fundamental issue that seems inevitable. Considering the importance of the above-mentioned issues, this paper examines the effect of hole diameter on the ultimate bearing capacity of hollow-core slabs using the finite element method. For this purpose, at first, the hollow-core concrete slab was modeled in in ANSYS software and then, for problem validation, it was compared with the laboratory model. After validation, the parameter of hole diameter was changed and the obtained results were evaluated. It should be noted that the changes was applied on four hollow-core slab of 1.5, 4, 6 and $9 \mathrm{~m}$ long shown in the studies. The maximum hole diameter of the slab can be used to reduce the weight of the slab and optimize the sections. This is because the ultimate bearing capacity of the hollow-core slab does not change as the diameter of the hole is reduced. In other words, by reducing the hole diameters in hollow slabs, their ultimate bearing capacity does not increase.
\end{abstract}

Keywords: Hollow-core slab, ultimate bearing capacity, hole diameter, finite element method.

\section{Introduction}

Today, in industrialized and developing countries, a huge portion of construction budgets and national capitals is spent for construction of concrete structures. Hence, the importance of saving materials, especially concrete in concrete structures has been recognized more than ever [1].

\footnotetext{
${ }^{*}$ Corresponding author: Structural Engineering MS, Guilan University

Email: Mohamad_maleknia@yahoo.com
} 
Many numbers of buildings that are already in operation were built from the hollow-core slab. The use of reinforced concrete hollow-core slabs in reducing the concrete placing volume and the cost and weight of structure is very important and effective.

In this paper, the effect of hole diameter on the ultimate bearing capacity of hollow-core slabs is examined using the finite element method.

ANSYS is a powerful software in the field of structural engineering and strengthening. As an analytical tool, it uses the finite element method for modeling and analysis. The Finite element method has been developed so as to solve complex problems with any geometry, material and loading. In this method, complex models can be initially divided into smaller solvable components, and then, by combining the results from solving each component together, the solution of overall model can be obtained at any point [2]. The considered sections in this paper are modeled and studied by the ANSYS software.

\section{Modeling}

In the present study, the impact of hole's diameter on final loading capacity of hollowcore slabs is addressed. First, for validation of models' behavior and the presented results of this research, a sample beam was modeled in ANSYS software and its physical and geometric properties were described. Then the loading-deformation diagram of the middle of the beam, the load inducing initial cracks in slab, final load and cracking pattern at the final second were investigated. Finally, the obtained results were compared with the results of Mohammad Mahdi Salehi Yanehsari and Ali Modanlo work entitled "bending and bending-shear enforcement of armed concrete hollowcore slabs by CFRP and GFRP fibers and steel sheets" [3]. In the mentioned work [3] the final loading capacity of U-boot armed concrete slabs, alone and enforced with FRP and steel sheets, were compared by experimental models. However, at the present study, only the first part of the mentioned study was used for validation of results. For this purpose, an armed concrete hollowcore slab $(150 \times 45 \times 20 \mathrm{~cm})$ with corresponding tension armature ratio was fabricated according to ABA regulation. 6 ribbed rebar (No 12) were used as tension armature and 4 rebar (No 8) were applied as compressive rebar. 6-mm diameter shear armatures were placed with center-to-center distance of $10 \mathrm{~cm}$ (at lateral one third) and $20 \mathrm{~cm}$ (at middle three fifth). Also number 6 rebar with center-to-center distance of $15 \mathrm{~cm}$ were employed as thermal rebar at the top and bottom and perpendicular to the main rebar. Two opening with $10-\mathrm{cm}$ diameter were created at the entire length of slab. Features and method of armature-placement are shown in figure 1.
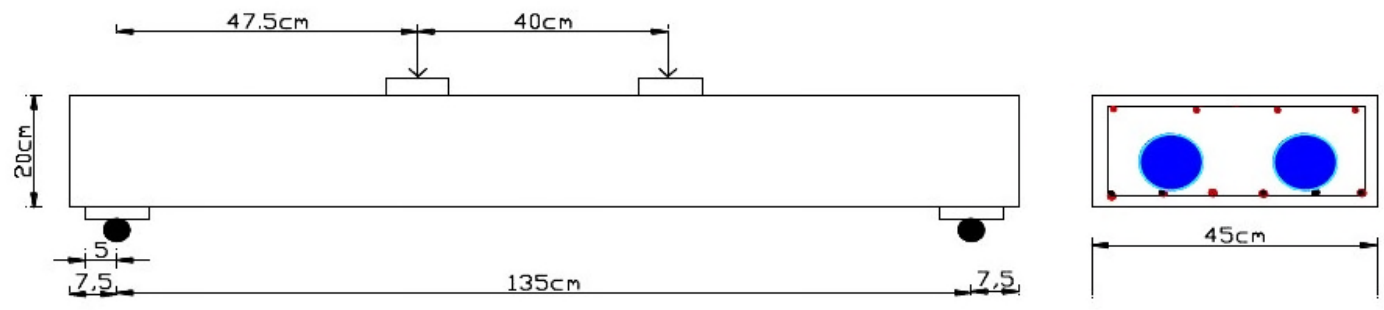

Figure 1: Slabs specifications [3] 


\section{Applied elements}

In ANSYS software, 8-element and 8-node solid 65 was employed for concrete modeling, Link180 bar and two-node elements were used for modeling of metal plates under the support and Solid 45 was applied for modeling of metal plate under the concentrated load (to lower the impact of stress concentration).

\section{Physical properties}

The properties of concrete for the control hollow slab are shown in Table 1, and the properties of steel assuming the steel being a perfect elasto-plastic material are shown in Table 2.

Table 1: Properties of control slab concrete

\begin{tabular}{|c|c|c|}
\hline \multirow{2}{*}{ Control Slab } & $\mathrm{E}_{\mathrm{cu}}(\mathrm{Mpa})$ & $\mathrm{f}_{\mathrm{c}}(\mathrm{Mpa})$ \\
\cline { 2 - 3 } & 25000 & 25 \\
\hline
\end{tabular}

Table 2: Properties of control slab steel

\begin{tabular}{|c|c|c|c|}
\hline \multirow{2}{*}{ Control Slab } & $\begin{array}{c}\text { Modulus of Elasticity } \\
\left(\mathrm{E}_{\mathrm{s}}\right)\end{array}$ & Yielding Strength $\left(\mathrm{f}_{\mathrm{y}}\right)$ & Poisson's Ratio (v) \\
\cline { 2 - 4 } & $200000 \mathrm{Mpa}$ & $400 \mathrm{Mpa}$ & 0.3 \\
\hline
\end{tabular}

\section{Beam geometry and the method of armature-placement}

For investigation of hollowcore slab behavior, a slab $(150 \times 45 \times 20 \mathrm{~cm})$ was fabricated and two holes with diameter of $10 \mathrm{~cm}$ were created in the middle and along the length of slab, which can be seen in figure 2 and 3 .
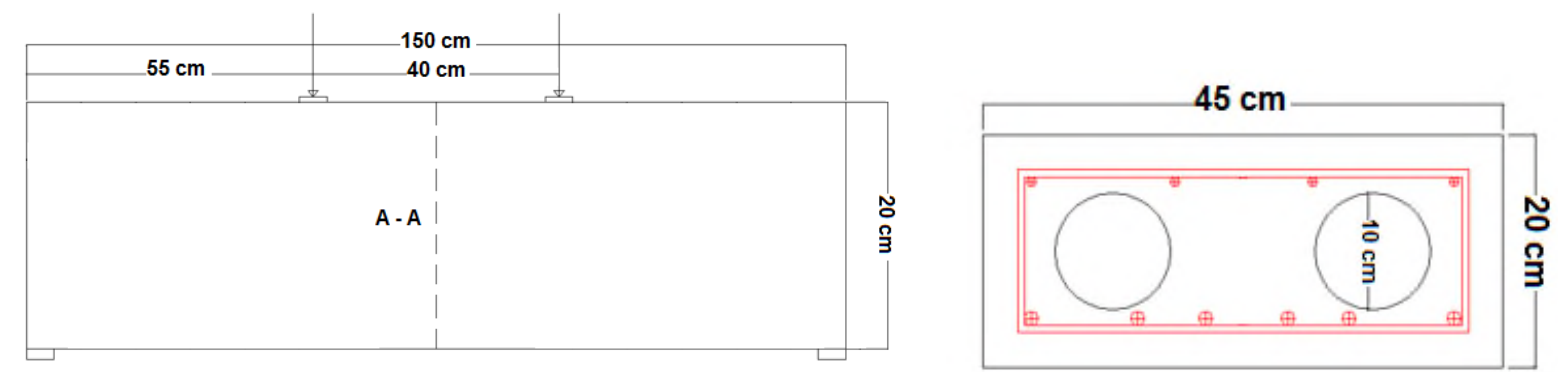

Figure 2: Slabs specifications 


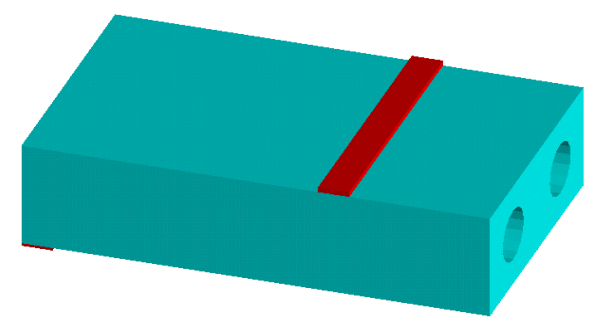

Figure 3: A-A section

\section{Validation of the presented model}

In this section, the results of finite element model and those obtained from experimental studies were compared. The conducted comparisons are: load-displacement diagram, crack distribution during loading and stress value in hollowcore slab.

\subsection{Load-displacement diagram in reference model}

To ensure the validity of the modeled developed by ANSYS software, the results were compared with work of Yanehsari and Modanlo [3].

Figure 4 shows good agreement of the results of finite element model with the experimental ones. Also, regarding table 3 and investigation of numerical results and the constructed model in ANSYS software, the difference was $3 \%$ which is considered as an acceptable.

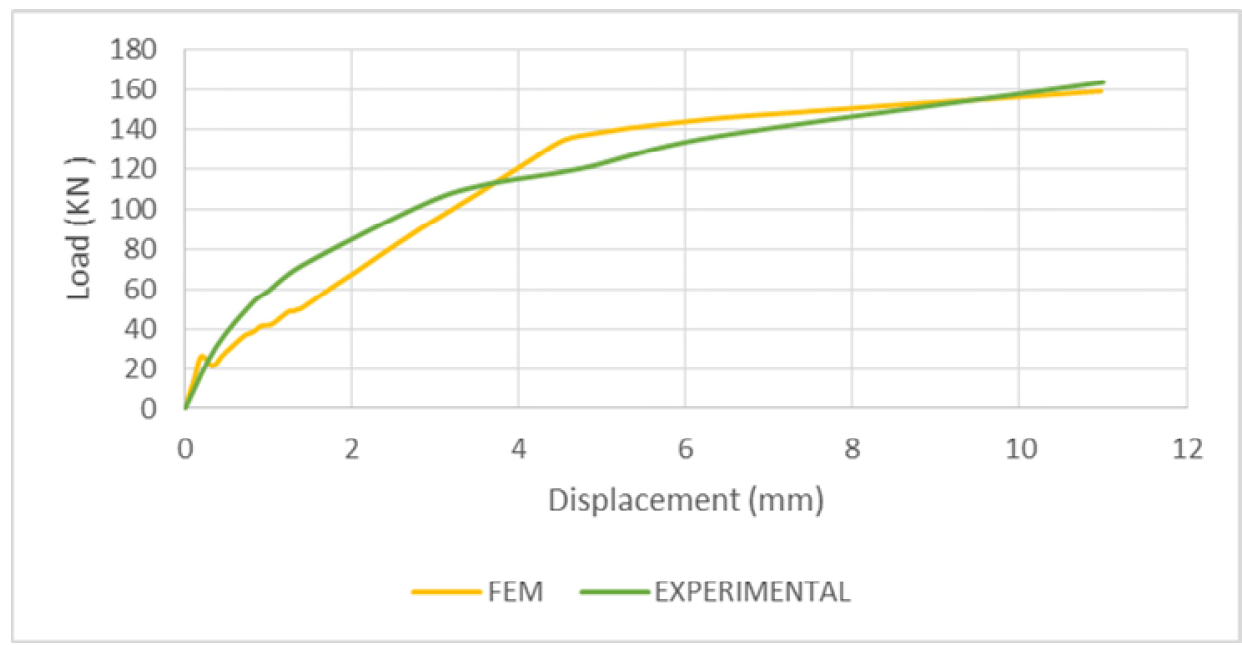

Figure 4: Load - Displacement diagram

Table 3: Comparison of the Results from Control Slab

\begin{tabular}{|c|c|}
\hline Ultimate load $(\mathbf{K N})$ & Control slab \\
\hline 165 & Laboratory sample \\
\hline 160 & Numerical analysis \\
\hline $3 \%$ & Error percentage \\
\hline
\end{tabular}




\subsection{Study of Crack Distribution during the Loading}

Figure 5 shows the cracked model of the laboratory sample and figure 6 shows evolution of crack pattern in the hollow core slab in different steps of loading.

As it is observed in the figures, in the control slab crack pattern, the cracks have been of flexural (90 degrees) type. Also, these cracks have been increased due to load increase and the slab has been ruptured due to flexural cracks. Considering the laboratory model of Yanesari and Ali Modanlou [3] shown in figure 5, a good correspondence is observed among the limit element cracked model and the laboratory model.

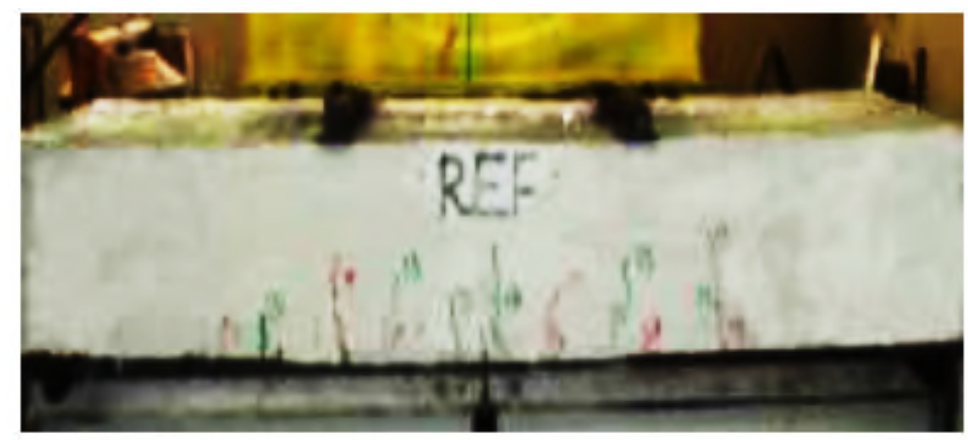

Figure 5: Cracked model of the laboratory
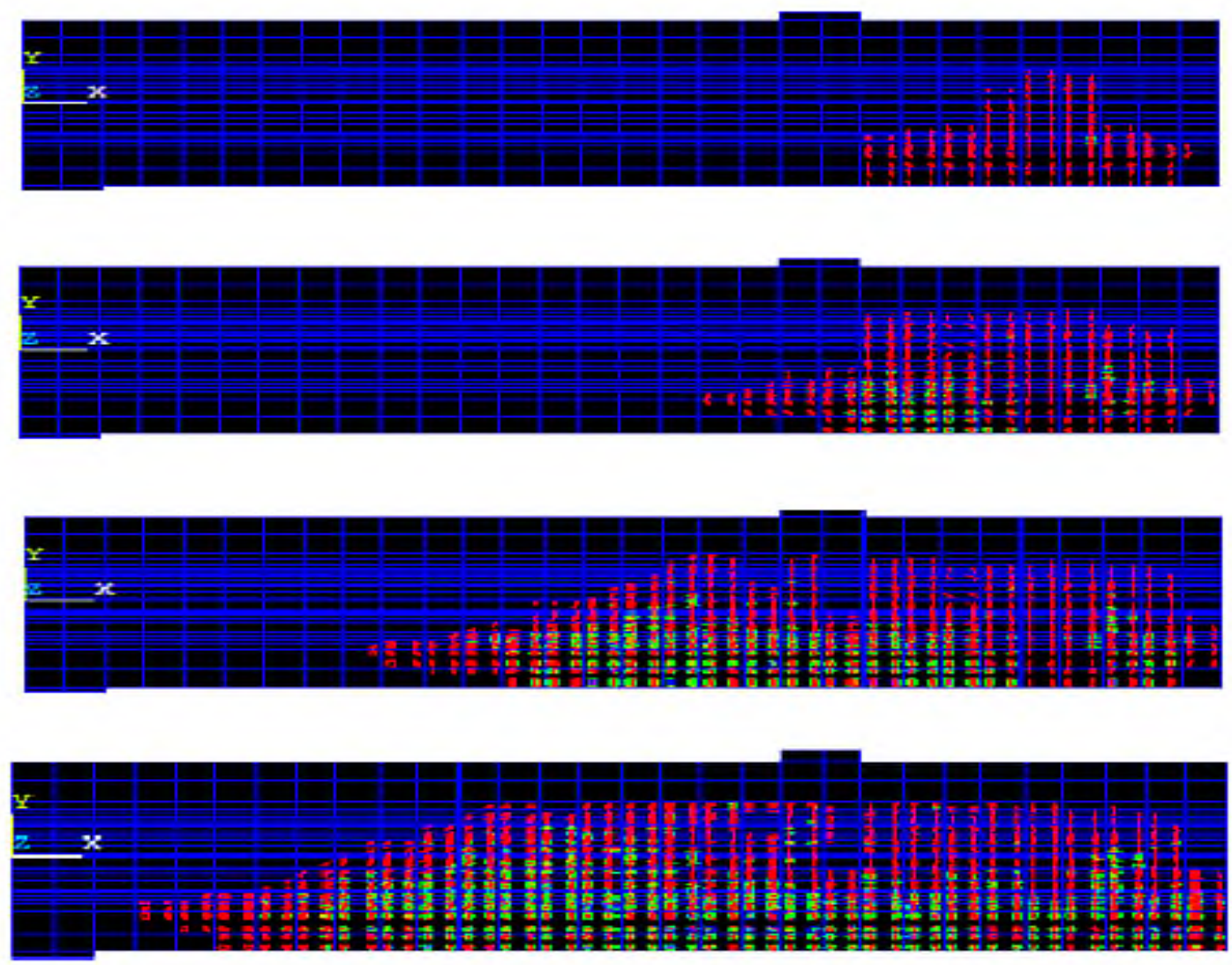

Figure 6: Evolution of crack pattern in the control slab 


\subsection{Study of Stress Rates in the Slab}

Considering figure 7 which shows Von Mises stress, it is observed that in final steps of loading the slab, in the compressive part, stress has reached its ultimate rate of compressive strength and also, it is observed in figure 8 that stress rates in tensional rebars $(6$ number 11 rebars placed in the lower part) have reached their flow rate in final step of loading.
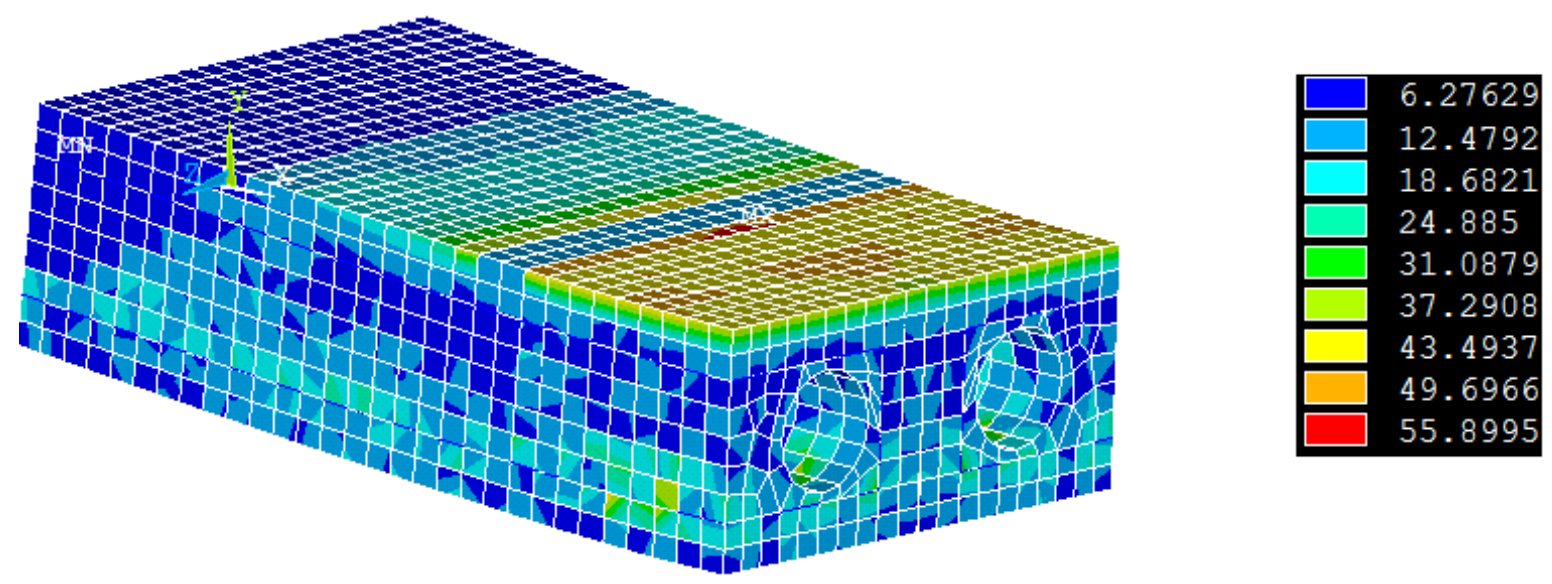

Figure 7: Von Mises stress in concrete voided slsb
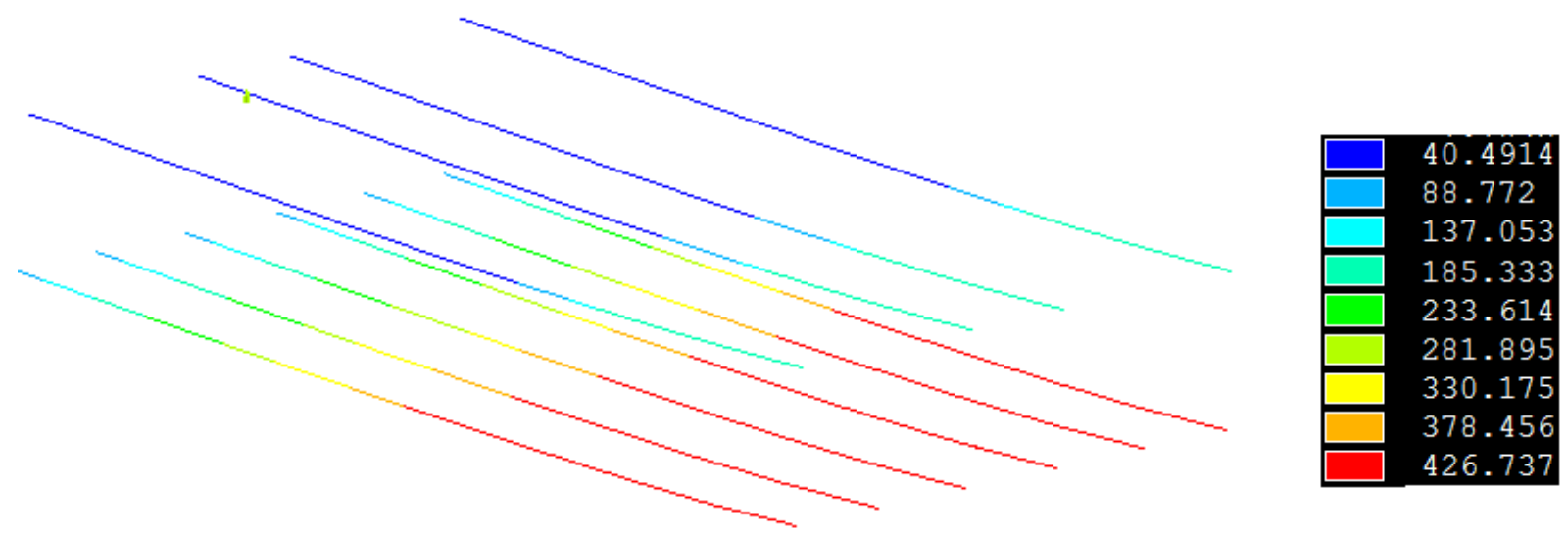

Figure 8: Stress flow in slab tensional rebars

\section{Evaluation of ultimate capacity of hollow-core slab by changing parameter of slab hole diameter}

After verification and validation of the reference slab as shown in the previous section, some numerical studies are reviewed that focus on the calculation of the ultimate bearing capacity of the hollow-core slab by changing the hole diameter parameter of slabs. To do this, the considered slab is modeled using ANSYS and then, the capacity of the hollow slabs is evaluated by changing the hole diameter parameter $(5$ and $10 \mathrm{~cm})$ for slabs of 1.5, 4, 6 and 9 m long. 


\subsection{Evaluation of ultimate bearing capacity of hollow-core slab by reducing hole diameter of $1.5 \mathrm{~m}$ long model}

To investigate the effects of changing the hole diameter of hollow-core slabs, two separate slabs with identical dimensions of $150 \times 45 \times 20 \mathrm{~cm}$ were modeled. In the first sample, two holes with the diameter of $10 \mathrm{~cm}$ and in the second sample, two holes with the diameter of 5 $\mathrm{cm}$ were created in the middle and along the length of the slabs. As shown in the loaddisplacement chart of Figure 9, it is observed that by reducing the hole diameter, no significant change in the ultimate bearing capacity of the hollow - core slab is seen.

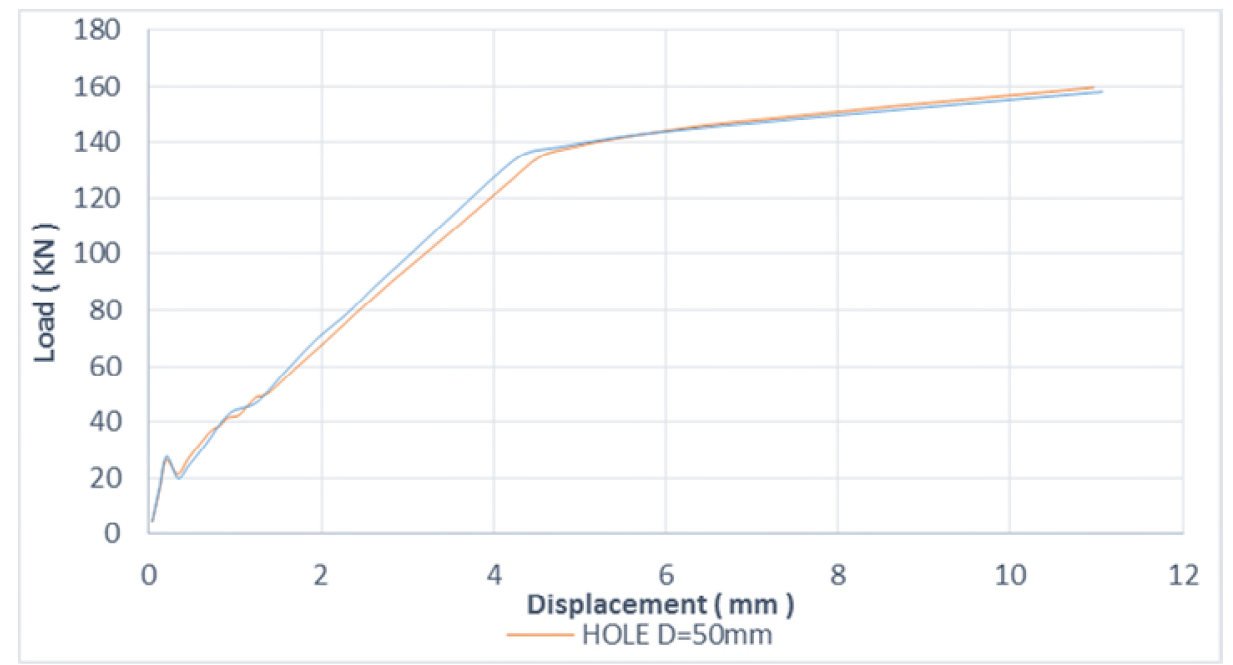

Figure 9: Load-displacement chart in $1.5 \mathrm{~m}$ long model

\subsection{Evaluation of ultimate bearing capacity of hollow-core slab by reducing hole diameter of $4 \mathrm{~m}$ long model}

To investigate the effects of changing the hole diameter of hollow-core slabs, two separate slabs with identical dimensions of $400 \times 45 \times 20 \mathrm{~cm}$ were modeled. In the first sample, two holes with the diameter of $10 \mathrm{~cm}$ and in the second sample, two holes with the diameter of 5 $\mathrm{cm}$ were created in the middle and along the length of the slabs. As shown in the loaddisplacement chart of Figure 10, it is observed again that by reducing the hole diameter, no significant change in the ultimate bearing capacity of the hollow - core slab is seen. 


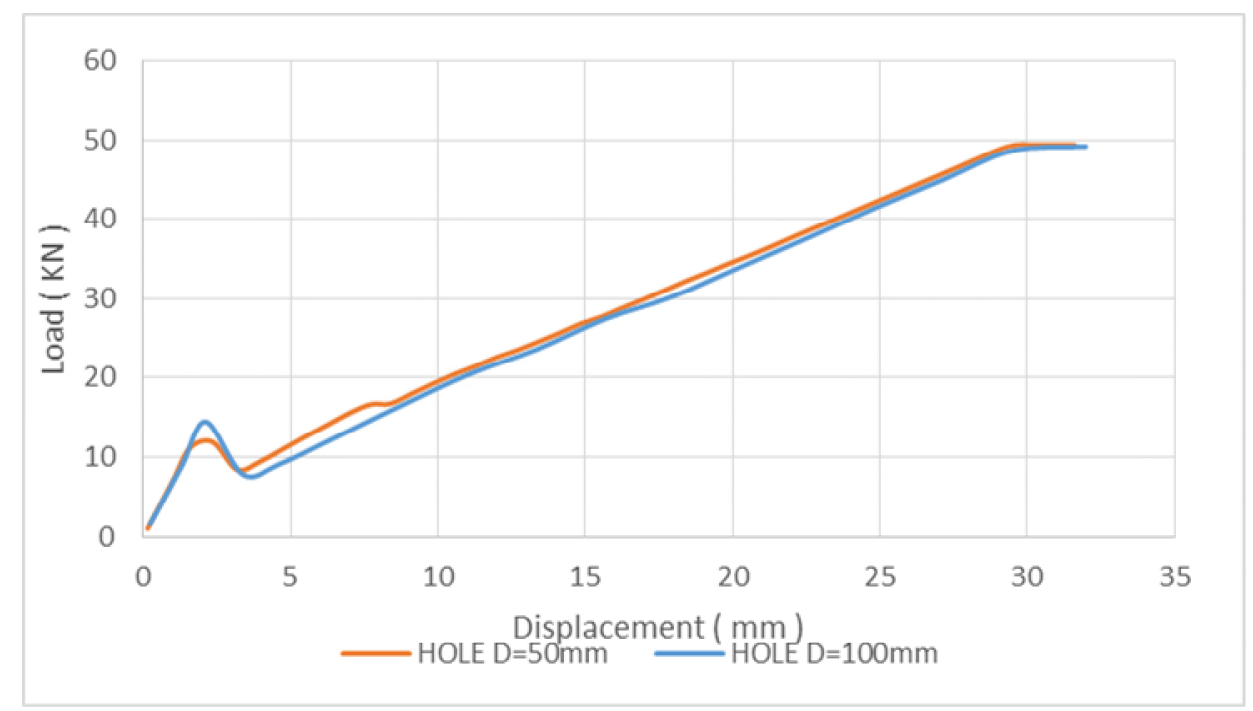

Figure 10: Load-displacement chart in $4 \mathrm{~m}$ long model

\subsection{Evaluation of ultimate bearing capacity of hollow-core slab by reducing hole diameter of $6 \mathrm{~m}$ long model}

To better evaluate the effects of changing the hole diameter of hollow-core slabs, in the third step, separate slabs with identical dimensions of $600 \times 45 \times 20 \mathrm{~cm}$ were modeled. In the first sample, two holes with the diameter of $10 \mathrm{~cm}$ and in the second sample, two holes with the diameter of $5 \mathrm{~cm}$ were created in the middle and along the length of the slabs. As shown in the load-displacement chart of Figure 11, it is observed for new dimensions that by reducing the hole diameter, no significant change in the ultimate bearing capacity of the hollow - core slab is seen.

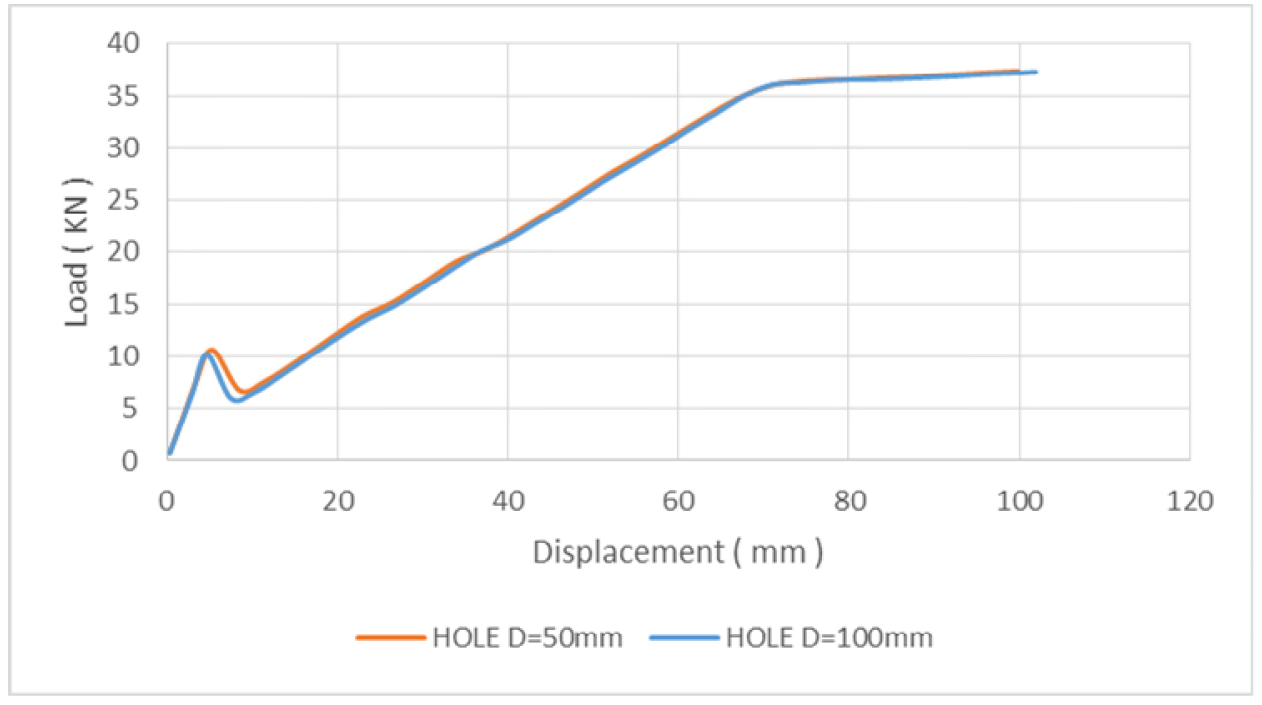

Figure 11: Load-displacement chart in $6 \mathrm{~m}$ long model 


\subsection{Evaluation of ultimate bearing capacity of hollow-core slab by reducing hole diameter of $9 \mathrm{~m}$ long model}

To better evaluate the effects of changing the hole diameter of hollow-core slabs, in the last step, separate slabs with identical dimensions of $900 \times 67.5 \times 30 \mathrm{~cm}$ were modeled. In the first sample, two holes with the diameter of $10 \mathrm{~cm}$ and in the second sample, two holes with the diameter of $5 \mathrm{~cm}$ were created in the middle and along the length of the slabs. As shown in the load-displacement chart of Figure 12, for the provided dimensions, by reducing the hole diameter, no significant change in the ultimate bearing capacity of the hollow - core slab is seen.

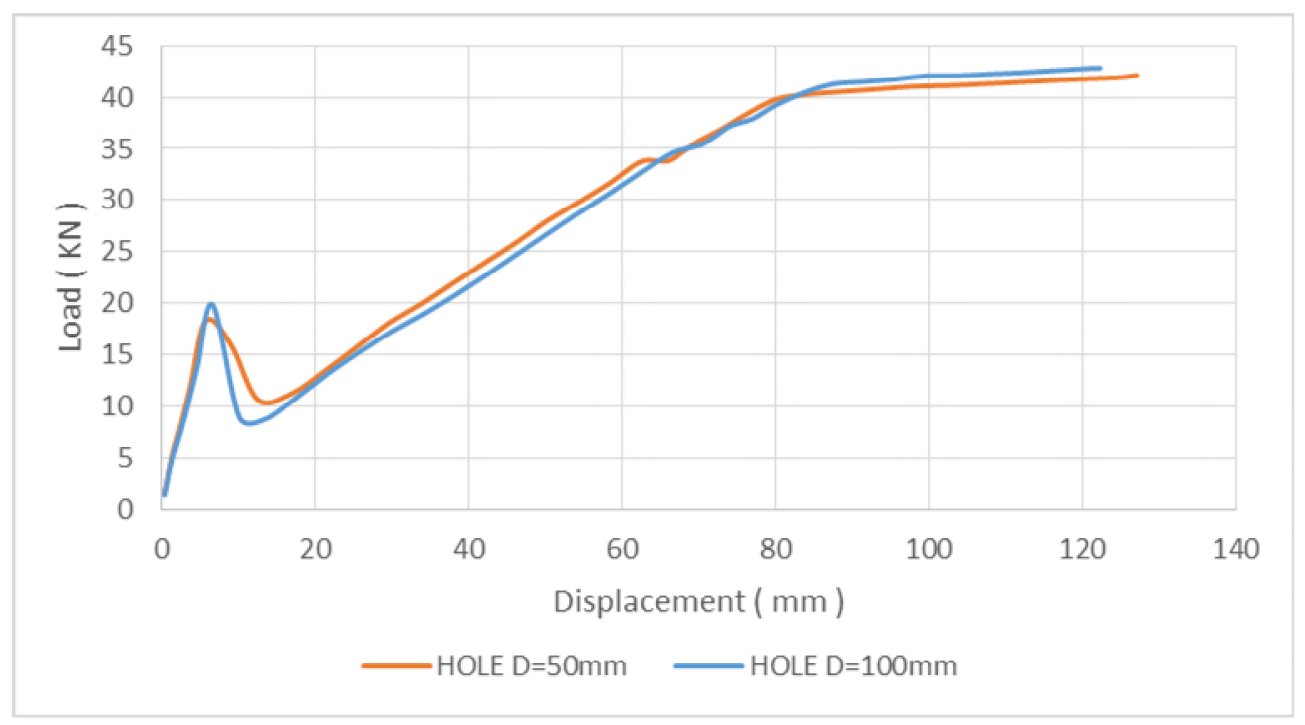

Figure 12: Load-displacement chart in $9 \mathrm{~m}$ long model

\section{Conclusions}

Today, with the increasing development of new technologies in the construction industry, the research and planning have directed to preserve national resources and avoid waste of materials and national capitals. In addition to greatly satisfying the mentioned needs, the reinforced concrete hollow-core slabs have received a lot of interest due to having positive aspects, such as economic, administrative, technical and architecture advantages. Given that the diameter of the holes in the hollow-core slabs are appeared to be necessary in order to achieve both the bearing capacity parameter and reduction in the volume of concrete placing, the effect of hole diameter on the bearing capacity of the hollow-core slabs was reviewed in this paper using the finite element method. For this purpose, a hollow-core slab was selected as a control (reference) slab. Then, the considered slab was modeled using ANSYS software, and after sample validation, the effects of changes in the parameter of hole diameter in the slabs of varying lengths were explored from which the following results were obtained: 
The maximum hole diameter of the slab can be used to reduce the weight of the slab and optimize the sections. This is because the ultimate bearing capacity of the hollow-core slab does not change as the diameter of the hole in all modeled samples is reduced. In other words, by reducing the hole diameter and increasing the volume of concrete placing in hollow-core slabs, their ultimate bearing capacity does not increase.

\section{References}

[1] Precast Pre-stressed Hollow-Core Slabs, Road Research Center, Housing and Urban Development, Department of Road and Urban Development.

[2] Finite Element Analysis Using ANSYS, Mohammad Reza Shaban Ali, Nas Publications, 2001.

[3] Bending and Bending-Shear Reinforcements of Reinforced Concrete Hollow-Core Slabs using CFRP and GFRP fibers and steel sheets, the Ninth National Congress of Civil Engineering, Mohammed Mehdi Salehi Yanesari and Ali Modanloo, May 2012. 